Programa de Residência Pedagógica na Licenciatura em Informática: partilhando possibilidades

\title{
O ENSINO DA MATEMÁTICA POR MEIO DO USO DAS TECNOLOGIAS DA INFORMAÇÃO E DA COMUNICAÇÃO
}

\author{
Kalianne Medeiros Feitosa ${ }^{1}$, Louize Gabriela Silva de Souza ${ }^{2}$
}

\section{PALAVRAS-CHAVE}

Tecnologias da Informação;

Ensino de Matemática;

Aprendizagem.
RESUMO

O presente capítulo versa sobre o uso das Tecnologias da Informação e Comunicação (TIC's) como ferramenta para auxiliar no ensino da Matemática e como forma de facilitar os processos de ensino e de aprendizagem. Sabemos que as TIC's são primordiais em muitas situações, utilizá-las nos processos de ensino e aprendizagem é uma forma lúdica de mediar à construção do conhecimento. Esse estudo é um relato de experiência realizado na Escola Estadual Poeta Renato Caldas, localizada em Assu/RN. Nessa escola-campo, as TIC'S contribuíram para o aprendizado de alunos do sexto ano, na disciplina de Letramento Matemático. Essa colaboração ocorreu por meio da produção de portfólio que os alunos produziram enquanto estavam utilizando a ferramenta. Com a mediação, eles observaram novas formas assertivas de aprender. Também foi observado que as notas dos alunos aumentaram no bimestre em que participaram da experiência.

\section{INTRODUÇÃO}

A sociedade moderna convive com o constante avanço da ciência e da tecnologia. Para que a educação seja afetada positivamente por esse avanço, é imprescindível que o docente acompanhe essas evoluções, incluindo em seus planejamentos o uso das Tecnologias da Informação e de Comunicação (TIC's).

Sobre as TIC's, Ramos e Carmo (2008, p. 32) afirmam,

As tecnologias da informação ou como conhecemos atualmente as novas tecnologias da informação e comunicação são o resultado da fusão de três vertentes técnicas: a informática, as telecomunicações e as mídias eletrônicas. Elas criaram no meio educacional um encantamento em relação aos conceitos de espaço e distância, como as redes eletrônicas e o telefone celular, que nos proporcionam ter em nossas mãos o que antes estava a quilômetros de distância.

Com relação ao ensino da Matemática, as TIC's podem auxiliar o professor no que diz respeito ao dinamismo dos processos de ensino e de aprendizagem, uma vez que essas permitem estabelecer conexões práticas com outros componentes curriculares e, assim, incentivar os alunos a explorarem as potencialidades.

${ }^{1}$ Graduando do Curso Superior de Licenciatura em Informática no Instituto Federal de Educação, Ciência e Tecnologia do Rio Grande do Norte (IFRN) - Campus Ipanguaçu. E-mail: kalianne_medeiros@hotmail.com

2 Professora Efetiva do Instituto Federal de Educação, Ciência e Tecnologia do Rio Grande do Norte (IFRN) - Campus Ipanguaçu. E-mail: louize.gabriela@ifrn.edu.br 
Sobre esses avanços e a postura do professor, Borba e Penteado (2003, p. 6465), assim se expressam,

[...] À medida que a tecnologia informática se desenvolve, nos deparamos com a necessidade de atualização de nossos conhecimentos sobre o conteúdo ao qual ela está sendo integrada. Ao utilizar uma calculadora ou um computador, um professor de matemática pode se deparar com a necessidade de expandir muitas de suas ideias matemáticas e também buscar novas opções de trabalho com os alunos. Além disso, a inserção de TI no ambiente escolar tem sido vista como um potencializador das ideias de se quebrar a hegemonia das disciplinas e impulsionar a interdisciplinaridade.

A introdução das TIC's nas aulas de Matemática, como de qualquer outra disciplina, não é uma tarefa fácil, pois requer, por um lado, que o professor esteja constantemente atualizado para dominar as novas tecnologias e explorá-las na sala de aula e, por outro, que o governo fomente as condições materiais na área de informática no chão das escolas e promova a formação continuada dos professores.

Vale ressaltar que a informática e suas tecnologias devem ser utilizadas para facilitar e diversificar o aprendizado e não apenas como substituta dos demais recursos. Sobre isso, Santos $(2009$, p.43) diz: “o desafio para o professor é ensinar com tecnologia, ou seja, empregar uma sequência didática em que o computador, através de um software educativo, seja utilizado para desenvolver um conteúdo." Ou seja, o professor deve incluir o computador e/ou outros recursos tecnológicos em seu plano de aula, para que os alunos venham construir o conhecimento por intermédio dele e não apenas enxergá-lo com algo meramente ilustrativo.

Diante disso, o objetivo deste capítulo é demonstrar que o uso das TIC's pode facilitar o ensino e a aprendizagem na disciplina de Matemática, pois dinamiza as aulas e desperta o interesse dos alunos por novos conhecimentos.

Para tanto, faremos um relato de experiência na Escola Estadual Poeta Renato Caldas, do município de Assu/RN, sobre o uso das TIC's e o desenvolvimento dos alunos através delas. Apontaremos alguns desafios e as perspectivas que o uso desses recursos pode acarretar, e observar o papel do professor como mediador nessas mudanças em sala de aula. Por último, trataremos do Programa de Residência Pedagógica, o qual proporcionou a experiência consubstanciada.

\section{AS TIC'S COMO FERRAMENTAS QUE AUXILIAM NOS PROCESSOS DE ENSINO E DE APRENDIZAGEM DA MATEMÁTICA: O PAPEL DO PROFESSOR}

As TIC's podem ser inseridas de uma forma bastante saudável em qualquer disciplina, cabendo ao professor como mediador do conhecimento buscar conhecer esses recursos e se apropriar deles para socializar em sala de aula. Caso contrário, os alunos tendem a se desinteressar, pois com a infinidade de informações que eles têm disponível através da internet, assumem que o professor é dispensável. 
Segundo Chagas (2010, p. 16),

[...] a profissão de professor sempre teve uma relação direta com livros, giz, quadro negro e papel. Nos últimos anos, isso mudou bastante. O universo de recursos do docente entrou em expansão - pode não abrir mão do material de sempre, mas incorpora hoje uma relação direta com as tecnologias $[\ldots]$ trazendo novas perspectivas para o ensino.

O que se espera da escola e dos professores, não só no ensino da Matemática, mas em todas as disciplinas, é que sejam inseridos os diversos recursos tecnológicos em suas aulas, e que estejam constantemente acompanhando o desenvolvimento do aluno na sociedade, pois a velocidade das informações cada vez aumenta, e o professor não pode e nem deve se tornar o último a saber, levando em consideração que um de seus papéis é mediar o conhecimento.

$\mathrm{O}$ aluno pode achar que sabe por ter acesso à informação, mas o papel do professor é ensinar a interpretá-las, e também a construir um conhecimento de mundo, contribuindo assim para uma aprendizagem significativa. Sobre isso, Ramos e Carmo (2008, p. 47), acrescentam,

[...] as tecnologias de informação e/ou comunicação possibilitam ao indivíduo ter acesso a milhares de informações e complexidades de contextos tanto próximos como distantes de sua realidade que, num processo educativo, pode servir como elemento de aprendizagem, como espaço de socialização, gerando saberes e conhecimentos científicos. Portanto, a internet deve ser utilizada como uma ferramenta de auxílio na aquisição da leitura e da escrita, ferramenta esta que a escola e o professor devem introduzir na vida escolar do aluno, visto que faz parte do cotidiano dos mesmos.

Segundo Kenski (2010, p. 23) “a possibilidade de acesso generalizado às tecnologias eletrônicas de comunicação e informação trouxe novas formas de viver, de trabalhar e de se organizar socialmente". Então, faz-se necessário que a escola busque acompanhar os avanços tecnológicos, para inseri-los em sala de aula e, assim, possibilitar dinamismo ao processo ensino e aprendizagem.

Diante de tantas transformações sociais, o professor enfrenta diversos desafios. Muitos acreditam que as tecnologias podem substituí-los em sala, e muitas vezes esse paradigma atrapalha a sua aproximação com as TIC's e utilização em suas aulas. Para Buzato (2001, p. 18),

Professores que creem, por exemplo, que seu papel no processo de ensino/ aprendizagem é o de fornecer informação, e que concebem os computadores como máquinas de armazenar informação podem sentir-se extremamente ameaçados, pois, em sua visão, o computador seria um professor eletrônico capaz de tomar-lhes o emprego. 
$\mathrm{O}$ avanço das tecnologias requer do professor uma postura diferenciada, e um olhar global. Nesse sentido, concordamos com Garcia, Norte e Messias (2012, p. 12) quando afirmam que,

[...] é necessário que os educadores se esforcem para: (a) reconhecer as necessidades dos alunos; (b) proporcionar ferramentas aos aprendizes para que possam refletir sobre a aprendizagem e sobre suas práticas atuais e (c) ter a consciência de que o educando é um ser humano que traça constantemente novas buscas pelo saber.

Tendo essa compreensão, o educador vai poder ter um maior aproveitamento de suas aulas, pois irá passar a ter como objetivo observar o educando e suas necessidades gerais, e assim construir junto com eles a aprendizagem. Utilizando essas estratégias, o educando tem maior liberdade em construir suas próprias ideias sobre determinado problema, seja ele matemático ou não.

A esse respeito, Martins (2009, p. 3) acrescenta que "as tecnologias, em especial o computador e a internet, usadas como um meio e não como um fim, podem ter um precioso efeito no estímulo e na motivação do aluno para as atividades, envolvendo-o nas matérias durante o processo de Ensino-Aprendizagem".

Assim, o aluno passa a se sentir mais necessário em sala de aula, visto que ele irá construir o conhecimento junto com o professor através dos recursos tecnológicos.

\section{RELATO DA EXPERIÊNCIA DO PROGRAMA DE RESIDÊNCIA PEDAGÓGICA NA ESCOLA ESTADUAL POETA RENATO CALDAS}

A nossa experiência, como bolsista residente do Programa de Residência Pedagógica (PRP), se realizou na Escola Estadual Poeta Renato Costa, no município de Assu/RN, em 2019, com as turmas dos sextos anos. O desafio era fazer o diálogo da disciplina Matemática com a informática, mediante o uso das TIC's, ou seja, promover a interdisciplinaridade que, metodologicamente, pode ser entendida como trabalhar um determinado conteúdo de uma disciplina fazendo uso dos conhecimentos de outras.

Tendo em vista que os alunos dessa escola-campo, a exemplo de tantas outras, sentem dificuldades em aprender os conteúdos da Matemática, e que muitos deles ficam conectados com os seus celulares em sala de aula, destinando baixa atenção aos conteúdos que estão sendo ministrados, idealizamos utilizar recursos da informática para facilitar o ensino e ampliar a aprendizagem.

Vale ressaltar, que as tecnologias digitais e a Matemática já têm proximidade, conforme aponta D’AMBROSIO (1996, s/p):

Ao longo da evolução da humanidade, Matemática e tecnologia se desenvolveram em íntima associação, numa relação que poderíamos dizer simbiótica. A tecnologia entendida como convergência do saber (ciência) e do fazer (técnica), e a matemática são intrínsecas à busca 
solidária do sobreviver e de transcender. A geração do conhecimento matemático não pode, portanto ser dissociada da tecnologia disponível.

A experiência foi realizada com a disciplina de Letramento Matemático, que é ministrada às turmas dos sextos anos, as quais contam com alunos entre 12 e 13 anos de idade. Aplicamos em duas turmas, uma com 16 e outra com 24 alunos.

No início, houve dificuldades em entrelaçar os conteúdos que os alunos precisavam aprender, com os conhecimentos que eles precisavam ter sobre as ferramentas digitais que iriam ser utilizadas. Foi um momento pedagógico delicado considerando o foco nos conteúdos essenciais da referida disciplina. Gravina (1998, 57p.), afirma que:

[...] no contexto da Matemática, a aprendizagem nesta perspectiva depende de ações que caracterizam o "fazer matemática": experimentar, interpretar, visualizar, induzir, conjeturar, abstrair, generalizar e enfim demonstrar. É o aluno agindo, diferentemente de seu papel passivo frente a uma apresentação formal do conhecimento.

Para remover esse obstáculo, demonstramos que a utilização dos recursos tecnológicos facilita a aprendizagem da Matemática. Em seguida, realizamos uma atividade no laboratório de informática, utilizando a ferramenta online chamada Tabuada do Dino.

Essa ferramenta tinha como objetivo fazer com que os alunos compreendessem como funciona a tabuada e entender as relações que a tabuada da multiplicação tem com a da divisão por exemplo. Essa atividade foi bem aceita pelos alunos, que eram incentivados a interpretar os resultados e experimentar formas de resolver os problemas fazendo uso daquele recurso. Além disso, os alunos conseguiram compreender que a operação de multiplicação é inversa da divisão e vice-versa, e cada um criou sua própria técnica para aprender mais facilmente.

Também foi observado que as notas dos alunos aumentaram significativamente no bimestre em que foi utilizada essa ferramenta digital. Isto ratifica o que Santos (2009) afirma e nós concordamos: por meio das TIC's os alunos conseguem estabelecer ligações entre a Matemática e os conteúdos de outras áreas, utilizando-as como elemento interdisciplinar, o que possibilita dinamizar o processo de ensino e aprendizagem e contribuir para a formação do cidadão que se deseja protagonista na sociedade tecnológica vigente.

Durante todo o ano de 2019 foram desenvolvidas várias atividades envolvendo as TIC's com as duas turmas dos $6^{\circ}$ anos, dentre as quais podemos destacar o uso das ferramentas de escritório, o editor de texto, para que os alunos construíssem gráficos de barras para distribuírem os dados colhidos por eles na disciplina de Letramento Matemático.

Essas atividades desenvolvidas demonstraram como as $\mathrm{TIC}^{\prime} \mathrm{S}$ podem potencializar os saberes dos alunos, e até mesmo aqueles que não ficavam atentos às aulas, passaram a se interessar e a compreender. E aquele que compreendia, mas 
tinha dificuldade de organizar o seu raciocínio, passou a explorar esse conhecimento e a colocá-lo em prática.

Ao final do segundo bimestre, foi aplicado um questionário com alguns alunos dessas turmas, para avaliar a experiência, ou seja, para saber a opinião dos alunos sobre as atividades desempenhadas por meio das TIC's e se eles achavam que esses conhecimentos tinham feito a diferença em seu processo do ensino e aprendizagem. O Gráfico 1, revela o posicionamento dos alunos.

Gráfico 1: Os conhecimentos adquiridos por meio das TIC'S tiveram alguma diferença para o seu processo do ensino e aprendizagem?

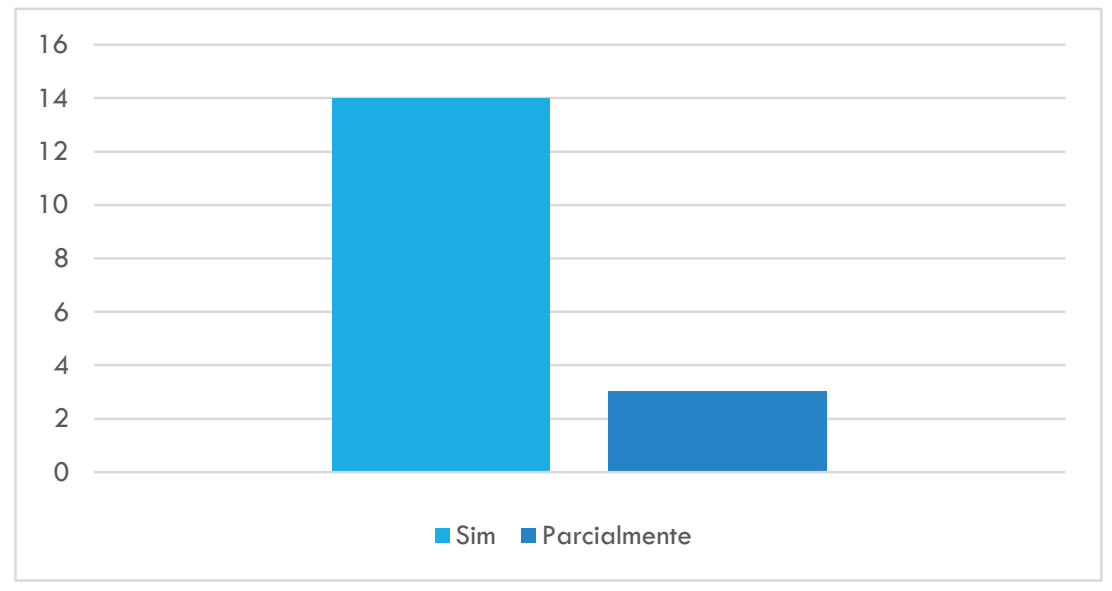

Fonte: Produzido pelas autoras, 2019.

Assim, podemos perceber que a maioria dos alunos que responderam ao questionário, entenderam que foram válidos os conhecimentos adquiridos por meio das TIC's e que estes auxiliaram em sua aprendizagem. Alguns alunos também justificaram as suas respostas, e relataram os pontos que mais tinham gostado nas aulas. Isto nos permite concluir que o diálogo entre as disciplinas facilita o ensino e a aprendizagem e que a utilização das TIC's em sala de aula precisa ser uma realidade fomentada.

\section{O PROGRAMA DE RESIDÊNCIA PEDAGÓGICA}

O Programa de Residência Pedagógica (PRP), uma das ações que integram a Política Nacional de Formação de Professores, foi instituído pela Portaria $n^{\circ} 38$, de 28 de fevereiro de 2018, da CAPES/Ministério da Educação, com a finalidade de apoiar Instituições de Ensino Superior na implementação de projetos inovadores que estimulem a articulação entre teoria e prática nos cursos de licenciatura, e por objetivos:

I. Aperfeiçoar a formação dos discentes dos cursos de licenciatura, por meio do desenvolvimento de projetos que fortaleçam o campo da prática e que conduzam o licenciando a exercitar de forma ativa a relação entre teoria e prática profissional 


\section{Kalianne Medeiros E Louize Gabriela}

docente, utilizando coleta de dados e diagnóstico sobre o ensino e a aprendizagem escolar, entre outras didáticas e metodologias;

II. Induzir a reformulação do estágio supervisionado nos cursos de licenciatura, tendo por base a experiência da residência pedagógica;

III. Fortalecer, ampliar e consolidar a relação entre a IES e a escola, promovendo sinergia entre a entidade que forma e aquelas que receberão os egressos das licenciaturas, além de estimular o protagonismo das redes de ensino na formação de professores; e

IV. Promover a adequação dos currículos e das propostas pedagógicas dos cursos de formação inicial de professores da educação básica às orientações da Base Nacional Comum Curricular (BNCC). (BRASIL, 2018).

Além disso, o PRP contempla, entre outras atividades, a regência de sala de aula e a intervenção pedagógica, acompanhadas por um professor da escola com experiência na área de ensino do licenciando e orientada por um docente da sua Instituição Formadora. (BRASIL, 2018). Ou seja, ele se propõe a aperfeiçoar a formação prática dos licenciandos, mediante a imersão no ambiente escolar, de modo que possam colocar em prática os conhecimentos adquiridos durante os seus respectivos cursos de licenciatura.

Por meio do PRP foi possível vivenciarmos experiências únicas e aperfeiçoar a nossa formação, pois participar imerso em uma sala de aula, acompanhando uma professora de Matemática e tomando conhecimento das dificuldades dos alunos nos ajudou a pensar em estratégias para melhor desenvolver o processo ensino e aprendizagem.

\section{CONSIDERAÇÕES FINAIS}

O uso das TIC's no ensino da Matemática ainda se constitui um grande desafio por diversos motivos, entre eles a falta de preparação dos professores e a infraestrutura das escolas. No entanto, o relato da experiência apresentado neste capítulo nos permite constatar o quanto as TIC's podem dinamizar e melhorar as aulas dessa disciplina e contribuir para o aprendizado significativo dos alunos.

Vimos que o papel do professor é de extrema importância nesse processo de inserção das TIC's, mas que também requer um novo posicionamento no olhar e no seu fazer, ou seja, os educadores precisam inserir cada vez mais esses recursos tecnológicos no planejamento de suas aulas e, assim, fomentando a diversificação e dinamização das aulas.

Para que isto se torne realidade é imprescindível que as políticas educacionais se voltem para viabilizar a infraestrutura de informática nas escolas e promovam a formação continuada dos professores, pois para desenvolver um trabalho interdisciplinar utilizando as TIC's é fundamental um laboratório completo de informática (hardware, software, internet etc.) e cursos de atualização para os professores. 
Para nós, bolsistas residentes, o PRP foi uma experiência valiosa, uma vez que nos oportunizou atrelar os conhecimentos obtidos durante o nosso curso de Licenciatura em Informática à disciplina Letramento Matemático, da Escola Estadual Poeta Renato Caldas, localizada no municipio de Assú/RN. A experiência desenvolvida por meio da interdisciplinaridade contribuiu de forma significativa para a melhoria das aulas e para o rendimento acadêmico dos alunos.

Destacamos também a contribuição para o nosso amadurecimento conceitual com relação ao tema TIC's, em tempos de céleres avanços tecnológicos, ratificando o entendimento de que a utilização das tecnologias digitais, particularmente, no ensino da Matemática, pode contribuir decisamente na contrução do conhecimento significativo dos alunos.

\section{REFERÊNCIAS}

BRASIL. Secretária de Educação Fundamental. Parâmetros curriculares nacionais: matemática. Brasília: MEC, 1998.

BRASIL. Ministério da Educação. Coordenação de Aperfeiçoamento Pessoal de Nível Superior - CAPES. Portaria $\mathbf{n}^{\mathbf{0}}$ 38, de 28 de fevereiro de 2018. Institui o programa de Residência Pedagógica. Brasília, DF: 2018a. Disponível em: http://www.in.gov.br/materia/-

/ asset_publisher/Kujrw0TZC2Mb/content/id/5230849/do2-2018-03-05-portaria-n38-de-28-de-fevereiro-de-2018-5230845. Acesso em: 2 jan. 2019.

BUZATO, M. E. K. O letramento eletrônico e o uso do computador no ensino de língua estrangeira: contribuições para a formação de professores. 2001. 188 f. Dissertação (Mestrado em Linguística Aplicada)-Universidade Estadual de Campinas, Campinas, 2001. Acesso em: 20 OUT. 2019

GRAVINA, Maria A; SANTAROSA, Lucila M.C. Informática da Educação: Teoria e Prática. Porto Alegre. Vol 1, n.2 (Abril.1999) A Aprendizagem da Matemática em Ambientes Informatizados. Disponível em:<https://lume.ufrgs.br/handle/10183/20962> Acesso em: 24 de outubro de 2019.

KENSKI, Vani Moreira. Tecnologias e o ensino presencial e a distância. 9 ed. Campinas, SP: Papirus, 2010.

LEITE, Werlayne S. S., RIBEIRO, Carlos A. de N. A inclusão das TICs na educação brasileira: problemas e desafios. Magis. Revista Internacional de Investigación en Educación Disponível em:<https:/ / www.redalyc.org/pdf/2810/281024896010.pdf>. Acesso em: 20 de outubro de 2019. 
MARTIN, Zélia. As TICs no ensino-aprendizagem da matemática. Universidade do Minho, 2009. Disponível em:

<http:/ / www.educacion.udc.es/grupos/gipdae/documentos/congreso/xcongreso Lpdfs/t7/t7c200.pdf>. Acesso em: 20 de Outubro de 2019.

MODROW, Elisabeth S. A; SILVA, Marcia B. Os desafios da escola pública paranaense na perspectiva do programa PDE (2013). A escola e o uso das TIC: limites e possibilidades. Disponível em:<http:// www.diaadiaeducacao.pr.gov.br/portals/cadernospde/pdebusca/prod ucoes_pde/2013/2013_uepg_ped_artigo_elizabeth_santanna_modrow.pdf> Acesso em: 25 de outubro de 2019 .

PACIEVITCH, Thais. Info Escola. Tecnologia da Informação e Comunicação. Disponível em: <https://www.infoescola.com/informatica/tecnologia-dainformacao-e-comunicacao/> Acesso em: 21 de outubro de 2019.

RAMOS, Francisca A; CARMO, Patricia E. R. Monografias Brasil Escola. As tecnologias de Informação e comunicação (TICS) no contexto escolar. Disponível em:<https://monografias.brasilescola.uol.com.br/educacao/as-tecnologias-

informacao-comunicacao-tics-no-contexto-escolar.htm> Acesso em: 23 de outubro de $\underline{2019 .}$

SANTOS, Marcelo A. Novas Tecnologias no ensino de matemática: possibilidades e desafios. Disponível em: < http:/ / www.pucrs.br/ciencias/viali/tic_literatura/artigos/tics/101092011085446. pdf> Acesso em 22 de outubro de 2019.

SANTOS, Rodiney M. B. Brasil Escola. Tic's: Uma tendência no ensino de matemática.

Disponível em:<https:// meuartigo.brasilescola.uol.com.br/educacao/tics-uma-tendencia-noensino-matematica.htm> Acesso em: 23 de outubro de 2019. 